\title{
Atividades lúdicas no meio aquático: possibilidades para a inclusão
}

\author{
José Francisco Chicon ${ }^{*}$ \\ Maria das Graças Carvalho Silva de Sá** \\ Alaynne Silva Fontes ${ }^{* * *}$
}

\begin{abstract}
Resumo: A pesquisa objetiva compreender e analisar a ação mediadora do professor no desenvolvimento de atividades lúdicas no meio aquático e a interação de uma criança autista com os colegas não deficientes nas aulas. A metodologia baseia-se em um estudo qualitativo do tipo estudo de caso. Os sujeitos foram 14 crianças da Educação Infantil da Universidade Federal do Espírito Santo (UFES) com desenvolvimento típico e uma com autismo, oriunda da comunidade da cidade de Vitória no Espírito Santo(ES). Conclui que as atividades lúdicas no meio aquático foram benéficas para a criança autista, tanto no sentido da ampliação de seus movimentos e vivências de brincar, como também em suas relações com os professores e colegas.
\end{abstract}

Palavras - chave: Educação Física. Equidade. Natação. Transtorno autístico.

\section{INTRODUÇÃO}

Com base nas considerações de Carmo (2002), quando analisamos o contexto que envolve a Educação Física Adaptada ${ }^{1}$, percebemos que, no campo dos esportes adaptados, muitos avanços

\footnotetext{
'Professor. Departamento de Ginástica e do Programa de Pós-Graduação em Educação Física do CEFD/UFES. Vitória, ES, Brasil. Coordenador e pesquisador do Laboratório de Educação Física Adaptada (LAEFA) UFES. Vitória, ES, Brasil. E-mail: chiconjf@yahoo.com.br

"Professora. Departamento de Ginástica do CEFD/UFES. Coordenadora e pesquisadora do Laboratório de Educação Física Adaptada (LAEFA/CEFD/UFES). Vitória, ES, Brasil. E-mail: gracasilvasa@gmail.com

"'-Graduanda. Curso de Bacharelado em Educação Física do Centro de Educação Física e Desportos/UFES, Vitória, ES, Brasil. E-mail: alaynnes.f@hotmail.com

${ }^{1}$ Campo de conhecimento que toma como foco o estudo acerca das possibilidades de desenvolvimento das pessoas com deficiência, bem como os grupos especiais, como idosos, gestantes, hipertensos, entre outros.
} 
têm sido feitos, especialmente no que se refere aos esportes paraolímpicos, fato este bem diferente do que constatamos em muitos espaços educativos regulares.

A Carta Internacional de Educação Física, produzida pela Organização das Nações Unidas para a Educação, Ciência e Cultura (UNESCO, 2010, p. 2), preconiza que "A prática da Educação Física e do desporto é um direito fundamental de todos" e seus programas "[...] devem ser concebidos em função das necessidades e das características pessoais dos praticantes [...]. Eles devem dar prioridade às necessidades dos grupos especialmente carenciados no seio da sociedade". Para que essa afirmação se legitime, faz-se necessário que as práticas pedagógicas, no âmbito da Educação Física, reconheçam que todos somos diferentes em nossa natureza biológica e desiguais em nossa natureza social (CARMO, 2002).

O autor nos conclama a não desconsiderar as diferenças e as desigualdades sociais, por conceber nesses itens os verdadeiros valores de fundamentação de nossas ações:

[...] independente do indivíduo ser paraplégico, hemiplégico, deficiente mental ou visual, [autista] não podemos negar-lhe a possibilidade de acesso ao conhecimento e às riquezas da humanidade que ele, de alguma forma, também ajudou a produzir, e que, por questões de poder e dominação, não tenha tido acesso. Entretanto, não precisamos, para conseguir isto, negar esse estado de diferença, de desigualdade, porque é na diferença e na desigualdade que devem repousar as bases de nossas ações e, seguramente, a primeira delas é no querer igualar o desigual (CARMO, 2002, p. 12).

Para tanto, será preciso repensar o tipo de formação oferecida (inicial e/ou continuada), no sentido de estabelecer redes com todos os campos de conhecimentos produzidos na/pela cultura, visto que, para compreender esse contexto, será preciso localizar esse ser em todas as suas dimensões tempo-espaço (SÁ, 2010).

Nesse bojo, urge que pesquisas sobre práticas pedagógicas sejam desenvolvidas, no sentido de apontar caminhos, estratégias, 
formas de interação e mediação, sensibilização, para que as crianças com deficiência possam encontrar, no contexto escolar e não escolar, um ambiente acolhedor, que lhes possibilite o acesso, permanência e sucesso.

Sendo assim, visando a contribuir na construção do conhecimento que favoreça os processos inclusivos de crianças com autismo pela via das diferentes possibilidades de pensar/produzir as atividades lúdicas no meio aquático, realizamos este estudo ${ }^{2}$.

Nessa mesma perspectiva, este artigo objetiva compreender e analisar a ação mediadora do professor no desenvolvimento de atividades lúdicas no meio aquático e a interação de uma criança autista com os colegas não deficientes nas aulas.

\section{LÚDICO E A CRIANÇA NO MEIO AQUÁTICO}

A cultura lúdica é antes de tudo um conjunto de procedimentos que possibilitam tornar o jogo possível. Jogo este que não se restringe a regras concretas, mas a regras vagas, de estruturas gerais, imprecisas que possibilita aos sujeitos do processo organizar jogos de imitação ou de ficção (BROUGÈRE, 2002).

Vários estudiosos, como Vygotsky (1991), Kishimoto (1998), Leontiev (1994), Victor (2000), Chicon (2004), dentre outros, têm evidenciado, em seus estudos, a importância e o papel do jogo no processo de aprendizagem e desenvolvimento da criança.

Ao direcionarmos esta discussão para o ensino da natação, podemos perceber que a maioria das metodologias desenvolvidas no contexto atual está fundamentada na "pedagogia tradicional/ tecnicista", que tem como objetivo primordial do processo de ensino/ aprendizagem o ensino do gesto técnico propriamente dito.

Em seus estudos, Fernandes e Lobo da Costa (2006, p. 5) também apontam nessa direção, ao afirmar:

\footnotetext{
${ }^{2}$ Como procedimentos de cuidados éticos, informamos que o presente estudo foi aprovado pelo Comitê de Ética em Pesquisa da Universidade Federal do Espírito Santo na data de 25 de agosto de 2010, com o número CEP 077/2010.
} 
Quando o ensino é focado no produto, aspectos como a etapa de desenvolvimento da habilidade do nadar em que o aluno se encontra, sua faixa etária, seus interesses e possibilidades físicas particulares não são considerados, o que pode tornar a aprendizagem da natação um processo monótono e sem significado para quem aprende e repetitivo e desinteressante para quem ensina.

$\mathrm{Na}$ busca por alternativas a esta perspectiva de pensar os processos de ensino/aprendizagem, especialmente no âmbito das aulas de natação, sem perder de vista o respeito a criança, com suas características, necessidades e peculiaridades, fizemos a aposta de envidar esforços em desenvolver uma proposta de ensino baseada nas atividades lúdicas no meio aquático. A exploração do corpo no espaço aquático constitui um componente essencialmente importante na construção da representação que a criança faz de si mesma em seu processo de desenvolvimento, especialmente em se tratando de crianças com autismo.

Nesse sentido, conforme assertiva de Damasceno (1992, p. 34), "[...] a natação, por ser uma das atividades que maiores benefícios propiciam ao desenvolvimento e, também, pela possibilidade de ser praticada sem restrições desde o nascimento, parece a mais indicada para a dinamização do potencial psicomotor do ser humano".

Ainda de acordo com o autor, a natação, compreendida como um desporto estruturado a partir de sua técnica, ritmo e regulamentação, vêm cada vez mais ampliando seu conceito acerca das atividades aquáticas pela via de relações criativamente lúdicas e recíprocas entre o indivíduo e o meio líquido, com vistas à sua potencialização.

Fernandes e Lobo da Costa (2006), reforçam essa constatação ao afirmarem que o meio líquido é identificado como um mundo de possibilidades de ação e movimentos potencializados, abandonandose o utilitarismo da modalidade natação, no que se refere ao aprender a salvar-se ou a salvar vidas na água, assim como a abordagem desportiva, voltada para o domínio mecânico e repetitivo, dos quatro estilos de nado. 
Nesse sentido, a água se torna facilitadora, uma vez que, pelo seu efeito de flutuação, provoca desafios e levará a criança a realizar movimentos mais livres, independentes, que, em ambiente terrestre, seriam difíceis de efetuar, favorecendo o desprendimento, a melhora da autoestima, a conquista do sentimento de confiança em si mesma, o desenvolvimento de ações colaborativas e da consciência corporal (SANTOS, 1996).

Durante as aulas de Educação Física no meio líquido é possível criar situações pedagógicas que tenham as ações lúdicas como cerne para estimular a melhor ambientação da criança nesse espaço, ampliar as interações sociais, o aprendizado dos gestos técnicos, como flutuação, respiração, propulsão, etc., a prática colaborativa e a aceitação das diferenças/diversidades de forma mais significativa para a criança. E ao fazer isso, o professor contribui para a organização socioafetiva e psicomotora da criança, em especial da criança com autismo.

A seguir, apresentaremos o conceito e as características que permeiam o autismo, estabelecendo relações com o contexto no qual o trabalho foi desenvolvido.

\section{A CRIANÇA COM AUTISMO NO CONTEXTO DAS ATIVIDADES LÚDICAS}

Este estudo investiga o processo de aprendizagem e de desenvolvimento de uma criança com autismo e está integrado às ações do projeto de extensão "Brinquedoteca: aprender brincando", desenvolvido no Laboratório de Educação Física Adaptada (LAEFA), Centro de Educação Física e Desportos (CEFD), Universidade Federal do Espírito Santo (UFES).

Como uma das atividades desse projeto de extensão, realizamos a proposta pedagógica "Atividades lúdicas no meio aquático", com o propósito de encadear uma prática educativa preocupada: a) com a aprendizagem e o desenvolvimento infantil por intermédio do brincar em ambiente líquido; b) em ampliar a trajetória do brincar das crianças 
participantes tenham elas deficiência ou não; c) em favorecer a experimentação corporal e a vivência simbólica; d) em promover a interação com os colegas e professores.

É nesse contexto que apresentamos as reflexões acerca do estudo de caso de um aluno com diagnóstico de autismo, inserido em uma turma de alunos de desenvolvimento típico.

Antes de iniciar com as reflexões do caso propriamente dito, é necessário refletir sobre os fundamentos teóricos para compreender os processos de aprendizagem e de desenvolvimento investigados. Podemos iniciar citando Leboyer (1987) e Orrú (2009), que apresentam o conceito de Leo Kanner sobre autismo, pela primeira vez, no ano de 1943, como uma doença da linha das psicoses, caracterizada por isolamento extremo, alterações de linguagem representadas pela ausência de finalidade comunicativa, rituais do tipo obsessivo com tendências à mesmice e a movimentos estereotipados.

O autismo é definido como um transtorno do desenvolvimento que geralmente está associado a outras síndromes e é facilmente confundido com deficiência intelectual. É descrito como uma síndrome comportamental e caracterizado por déficit na interação social, ou seja, dificuldade em se relacionar com o outro, déficit de linguagem e alterações de comportamento (ORRÚ, 2009).

Os relatos de Kanner apresentados por Leboyer (1987) destacam que, no autismo precoce, os sintomas aparecem no decorrer do primeiro ano de vida pós-natal e as crianças caminham antes de pronunciar as primeiras palavras. Crianças com esses sintomas costumam se isolar, evitam contato com os demais por meio do olhar e apresentam, com o passar do tempo, dificuldades na comunicação oral. Tanto crianças do sexo masculino, quanto as do sexo feminino podem ser afetadas.

De acordo com Leboyer (1987), na situação do "isolamento autístico", a criança é indiferente aos outros, ela os ignora e não reage à afeição e ao contato físico. Continuando em seu raciocínio, ele afirma que na primeira infância existe inaptidão da criança com 
autismo a brincar em grupo ou a desenvolver laços de amizade e que essas crianças mostram pouca emoção, pouca simpatia ou empatia por outro. Mas, o autor deixa entrar luz em suas reflexões ao enunciar: "À medida em que crescem (cerca de cinco ou seis anos) pode-se desenvolver uma maior ligação". E conclui nos fornecendo uma pista importante para o trabalho com crianças que apresentam autismo: "[...] se as anomalias das relações interpessoais estão invariavelmente presentes nos autistas desde sua tenra infância, é surpreendente constatar que os sintomas se atenuam quando a criança cresce" (p. 15-16).

Nesse sentido, é importante reconhecer e trazer ao contexto Vygotsky (1997), autor que já ressaltava, em suas pesquisas na década de 1930, que muito se estudou acerca das deficiências e suas características negativas, porém os estudos acerca de suas potencialidades seriam uma preocupação das investigações do futuro.

Negrine e Machado (2004) estão situados em um referencial que se preocupa com as possibilidades de aprendizagem de crianças autistas. Explicam que os primeiros sinais da síndrome de Autismo, em geral, não são logo percebidos pelos pais, embora, na maioria dos casos, tais sinais possam estar presentes desde os primeiros meses de vida.

Sendo assim, no trabalho com crianças que apresentam autismo, é importante saber que estratégias pedagógicas podem ser utilizadas para ajudá-las a avançar. Em nosso entender, o "brincar" é uma possibilidade pedagógica. Vygotsky (1991) relata que no brincar a criança cria uma situação imaginária que, em algumas circunstâncias, exercita níveis de compreensão cultural maiores do que a criança possui.

Em Vygotsky (1997), apreendemos que o ato volitivo das crianças com deficiência (autismo), para a experimentação corporal, necessita da ação mediadora do professor para provocar o contato corporal, seja para levá-las a interagir com os objetos, seja para dar segurança na realização de determinadas tarefas, ou ainda para fazêlas vivenciar experiências que não ocorrem sem implicação corporal. 
O autor ensina que não basta organizar os espaços disponibilizando materiais e objetos: é necessário definir estratégias de abordagem corporal e de intervenções pedagógicas.

O professor de Educação Física, para intervir com crianças autistas, deve estar preparado não apenas para propor, mas também para perceber as formas de expressão corporal do outro, para atender à sua demanda, para ser um companheiro presente em ajudá-las a superar as dificuldades com as quais se deparam.

Falkenbach, Diesel e Oliveira (2010, p. 207) nos orientam afirmando que,

As atitudes de ajuda que são oferecidas não ocorrem somente pelo contato físico, mas também pelo olhar, pela mímica, pela comunicação verbal, estimulandoas a realizar tarefas, estreitando as relações na formação de vínculos positivos, reforçando as conquistas mesmo quando parciais.

O processo de experimentação corporal nas práticas do projeto "Atividades lúdicas no meio aquático" volta-se mais para provocar situações relacionais a partir do brincar. Situações que possam auxiliar a criança no aprendizado e na descoberta de capacidades corporais, bem como nas reflexões e produções que realiza e protagoniza quando brinca no grupo.

\section{Metodologia}

Para Molina (1999), o estudo de caso não é em si uma eleição metodológica; é, sobretudo, a eleição de um objeto a estudar. Seguindo essa linha de raciocínio, pode-se afirmar que o estudo de caso se perfila perfeitamente na tradição da investigação qualitativa e, obviamente, não está esgotado por essa perspectiva metodológica.

O estudo se configura em uma pesquisa qualitativa de caráter descritivo e exploratório. Está orientado para a observação, registro e análise das atividades lúdicas desenvolvidas em meio líquido com 
uma turma inclusiva, em que uma criança com autismo interage no mesmo espaço-tempo com crianças de desenvolvimento típico.

Os sujeitos do estudo foram 15 crianças, de ambos os sexos, com idades de três anos, sendo 14 crianças do Centro de Educação Infantil da UFES (Criarte/UFES) com desenvolvimento típico e uma com autismo, oriunda da comunidade de Vitória-ES. Esses alunos foram atendidos no espaço da piscina por cinco estagiários do Curso de Educação Física, contando com o aluno bolsista, em um encontro semanal, no turno vespertino, das 14 às 15 horas, durante o segundo semestre letivo 2010/2, totalizando 12 aulas/registros.

A dinâmica inicial das aulas é caracterizada pelo acolhimento e a conversa inicial com as crianças sentadas na borda da piscina, quando buscávamos dialogar com elas sobre os acontecimentos da aula anterior e sobre as atividades previstas para aquele momento. Em um segundo momento da intervenção, nomeada de "atividades lúdicas no meio líquido", as atividades relacionadas aos fundamentos da natação eram realizadas - adaptação ao meio líquido, entrar e sair da piscina, deslocamento, cantigas de roda, flutuação, respiração, entre outras. Para finalizar, realizávamos com as crianças uma nova conversa a respeito das atividades vivenciadas durante a aula.

Com relação às ações pedagógicas que a equipe desenvolveu para apoiar a aprendizagem e a participação dos alunos no ambiente inclusivo, podemos citar, como principais, o trabalho em duplas e em pequenos grupos e a relação dialógica, em que explorávamos o tema das diferenças por meio de situações concretas e de curta duração, como: solicitar que as crianças olhassem para suas próprias mãos e, com o auxílio do estagiário, fossem percebendo as diferenças entre os dedos (tamanhos, função, formato). A partir desse olhar reflexivo, íamos estabelecendo uma relação com as diferenciações presentes entre elas. Por exemplo, mais baixa e mais alta, branca e negra, magra e gorda, mais quieta e mais dinâmica, uma criança que tem receio de entrar na água, outra que tem dificuldade de falar e de brincar no grupo, entre outras. Nesse processo, a intervenção pedagógica era conduzida de forma dirigida e mediada pelos estagiários. 
Durante o atendimento, os estagiários assumiram as seguintes funções: o aluno bolsista de iniciação científica atuou na coordenação das atividades, auxiliado por três estagiários, ficando o quinto estagiário com a função de filmar e fotografar as aulas. Para além desse momento, a equipe de pesquisa (o professor orientador, o aluno bolsista e os quatro estagiários envolvidos) se reunia logo após o atendimento para realizar a avaliação e planejamento do encontro seguinte (das 15 às 17 horas), havendo também outro encontro semanal na forma de grupo de estudo, com duração de duas horas.

Como instrumentos de coleta de dados foram utilizados a observação participante, vídeogravação das sessões e registros em diário de campo. Os dados foram analisados pela técnica de análise de conteúdos (BARDIN, 1994). O processo de análise das informações ocorreu por meio da elaboração de categorias que permitiram o agrupamento de questões significativas do conteúdo coletado. $\mathrm{O}$ procedimento permitiu organizar duas categorias: a) a relação da criança autista com os colegas; b) a mediação pedagógica do professor.

No desenvolvimento das descrições do aluno protagonista do estudo optamos por nos referir a ele chamando-o pelo pseudônimo de "Renato", e os professores/estagiários foram identificados pelos números $1,2,3,4$ e 5 .

\section{A RelaÇão da CRIANÇA AUtista COM OS COLEgas}

Para Vygotsky (1991), a aprendizagem é um processo social que influencia e modifica o desenvolvimento interno. Sua aposta está no fato de potencializar as relações sociais como fator que promove a aprendizagem. Assim sendo, as relações que propiciam modelos, orientação, compartilhamento de experiência e saberes favorecem os avanços internos da criança. A partir das observações realizadas, foi possível perceber que Renato se apegou afetivamente a um dos professores/estagiários, preferindo, por várias vezes, brincar apenas com ele. É como descreve a observação que segue: 
No momento inicial da aula, observamos que Renato estava inquieto e demonstrava nitidamente uma vontade de entrar na piscina. Os professores/ estagiários 1 e 2 tentaram sucessivamente se aproximar dele, convidando-o a brincar na água, sem sucesso. Foi observado que o aluno Renato, apesar de querer muito brincar naquele espaço, não apresentava um comportamento como em outros ambientes. Ele tentou morder e bater nos professores/estagiários. No entanto, quando o professor/estagiário 3 se aproximou, ele, com certa relutância, aceitou a acolhida, possibilitando ser auxiliado no desenvolvimento das brincadeiras na água, mas sem interagir com os colegas. Mesmo que ele fosse aproximado dos colegas pelo professor/estagiário 3, ele os ignorava (Diário de campo, em 21 set. 2010).

Percebe-se de imediato que o ambiente aquático delimita um espaço no qual há necessidade de outro adulto para dar segurança, provocar as situações de aprendizagem/brincadeiras, realizar a adaptação da criança ao novo ambiente. Nesse lugar, a criança com autismo é impelida a interagir com o professor/estagiário e a se comportar de uma maneira mais centrada e menos agitada, como não lhe é peculiar, contribuindo para o seu desenvolvimento. Apesar de a literatura destacar evidências acerca do distanciamento e da necessidade de isolamento da criança autista, é possível destacar um bom comportamento de relação com o professor que desenvolveu apego afetivo. Reconhecemos que a afetividade proporciona um excelente caminho para a aprendizagem. Assim, o fato de haver uma relação afetiva entre o professor e a criança possibilitou bons desempenhos na trajetória de brincar do aluno.

Apesar de a relação do Renato com seus colegas ser amigável, ele não costumava brincar com eles. Procurava com frequência o professor e brincava em sua companhia na maior parte da aula. Para que houvesse o contato com seus colegas, era preciso a ação mediadora dos professores/estagiários: 
Sempre ao iniciar a aula, após a rodinha de conversa, provocávamos uma cantiga de roda (borboletinha, sai piaba, o sapo não lava o pé, etc.) com os alunos dentro d'água. Observamos que Renato se interessava pela música. Frente a essa descoberta, passamos a usá-la como estratégia para mobilizar a atenção do aluno nas atividades. 'Sai piaba' (cantiga de roda 'Sai, sai, sai, ô piaba, saia da lagoa (bis). Põe a mão na cabeça, põe a mão na cintura, dá um remelexo no corpo, dá um abraço no outro') foi a música que nos mostrou, notoriamente, que Renato, ao ser estimulado por ela, interpreta e demonstra com o corpo, ao seu modo, os gestos indicados na letra da música. Assim, percebemos, após esta intervenção, que, em aulas anteriores, algumas crianças não o abraçavam e, no momento da música, aconteceu, para surpresa de todos os professores/ estagiários, esta interação entre eles. Nesta cena em destaque, o aluno em questão foi abraçado por três colegas que inicialmente tinham receio de ficar ao lado dele e se deixou abraçar, o que não é comum (Diário de campo, em 5 out. 2010).

A vivência do abraço dos colegas para Renato, proporcionada a partir da sensibilidade da música, foi uma experiência corporal diferenciada e que lhe propiciou muita satisfação. Também possibilitou um afastamento do professor preferido e o aproximou dos colegas do grupo. Nesse caso, a música foi o elemento mediador que facilitou e provocou a interação de Renato com os colegas, constituindo-se em uma boa estratégia, que, somada ao elemento água, mobiliza a criança com autismo, e também os outros colegas, a compartilhar experiências lúdicas, numa troca que enriquece a ambos. Brincar em companhia dos colegas foi significativo para Renato, pois the possibilitou estar mais presente na relação com eles, mais ainda em uma atividade satisfatória, elemento que o ajuda a entender a importância da relação com os parceiros. 


\section{A MEDIAÇÃo PEDAGÓGICA do PROFESSOR}

Vygotsky (1997) compreende a aprendizagem como fruto de uma ação social mediada pela cultura, ou seja, por meio do contato com o ambiente em que vive e com outras pessoas. Assim, a interação social com outras pessoas é essencial para o desenvolvimento do indivíduo.

O professor/estagiário falou aos alunos que eles iriam fazer de conta que estavam entrando em um quarto bem aconchegante e que alguns colegas estavam com muito sono. Pediu que, em duplas, um de frente para o outro, dessem as mãos formando uma cama. E começou a deitar os colegas mais sonolentos sobre a água, seguros por baixo pelos braços dos colegas (camas). Renato não compreendia a situação do jogo de faz de conta, se mostrou arredio a participar inicialmente, mas, com apoio do professor e junto com ele, fizeram a cama para um colega, mostrando satisfação com a situação. Em seguida, para nossa surpresa, dois coleguinhas pediram que ele dormisse na cama deles, e Renato, auxiliado pelo professor, deitou, ficando flutuando na água, apoiado pelos braços dos dois colegas. $\mathrm{Na}$ sequência, tomou a iniciativa de formar uma cama com um dos colegas, interagindo de forma mais ativa na brincadeira, mas ainda mediado pela ação do professor (Diário de campo, em 26 out. 2010).

Nesse recorte, percebemos que a ação mediadora do professor/ estagiário foi fundamental para colocar a criança com autismo em interação. Novamente o elemento água foi facilitador, possibilitando construir um clima de tranquilidade e aconchego, favorecedor das trocas socioafetivas entre os alunos. A mediação deve efetivamente atuar no espaço que marca o limite da capacidade da criança de caminhar sozinha (sem ajuda), até o máximo de sua capacidade com o apoio do outro. Nessas interações, o sujeito é ativo, portanto, é também responsável para captar e reelaborar o que lhe faz sentido desses contatos. 
Presenciamos nesse relato, também a iniciativa da criança com autismo para brincar. Segundo Falkenbach, Diesel e Oliveira (2010, p. 210), "A iniciativa para brincar é um comportamento interessante para avaliar o desenvolvimento da criança. A iniciativa está relacionada à segurança da criança, sua curiosidade e desejo exploratório, bem como o estabelecimento de iniciar-se com seus colegas, procurando-os para brincar". Essa não é uma atitude comum entre as crianças com autismo; ao contrário, elas tendem a brincar sozinhas.

Renato encontra-se afastado do grupo, sentado na
borda da piscina, indiferente aos acontecimentos.
O professor/estagiário 3 se aproxima levando um
espaguete (material de flutuação) e, tomando o aluno
nos braços, coloca-o sobre o objeto, como se fosse
um cavalinho. Começa a balançar o flutuador na
água como se estivesse a cavalgar. Renato mostra
entusiasmo com a situação e o professor o conduz
para junto dos colegas. Em seguida, participa de
uma corrida de cavalinhos de uma borda a outra da
piscina, se entregando à atividade e aos cuidados do
professor/estagiário, mas indiferente aos colegas
(Diário de campo, em 9 nov. 2011).

Na situação citada, percebe-se que é necessário que o professor tome iniciativa para provocar o contato corporal com a criança que apresenta autismo, seja para levá-la a interagir com os objetos, seja para dar segurança na realização de determinadas tarefas, seja para fazê-la vivenciar experiências que não ocorrem sem implicação corporal.

$\mathrm{Na}$ intervenção em turmas inclusivas, percebemos que o papel mediador do professor de Educação Física é decisivo no processo, isto é, o professor deve atuar com uma preocupação em atender às diferenças e, para cumprir esse papel, precisa agir como mediador nas relações dos alunos consigo mesmo, com os colegas e com os objetos, ajudando-os a superar as dificuldades que emergem do processo ensino-aprendizagem e orientando-os para que atinjam níveis de independência e autonomia. Conforme afirma Vygotsky (1991), 
o professor tem o papel fundamental de provocar avanços que não ocorreriam espontaneamente, como é possível observar na situação relatada.

Concordamos com Falkenbach (2005), quando afirma que a iniciativa para brincar também é um exercício de estímulo que parte dos professores. Auxiliar para brincar e obter confiança e iniciativa são aspectos educativos fundamentais para a aprendizagem da criança, que entendemos não podem ser descuidados no ato de educar.

\section{CoNSIDERAÇõES FINAIS}

As análises empreendidas nos oferecem indícios sobre as possibilidades de utilizar o lúdico como recurso pedagógico para promover o aprendizado e o desenvolvimento da natação em crianças em situação de inclusão.

Antes de finalizar as descrições do presente estudo, é importante destacar que as limitações biológicas do diagnóstico da síndrome de Autismo não impediram Renato de avançar em sua relação social e em sua trajetória do brincar nas atividades lúdicas no meio aquático. Tanto as relações como a forma de brincar obtiveram demonstrações de mudanças no processo de suas participações nas aulas. Um dos aspectos que melhor repercutiram sobre o aluno foi a satisfação demonstrada ao brincar e interagir nas aulas. Tal aspecto, no mínimo, pode ser contribuinte para o desenvolvimento e a ampliação de sua qualidade de vida, como também constatou Falkenbach, Diesel e Oliveira (2010) em suas pesquisas.

A partir do processo de coleta de informações, das aulas observadas, destacamos as seguintes considerações: a) apesar de o autismo ser conhecido pela dificuldade de relação social, a criança observada, com a experiência e participação nas aulas, demonstrou estar agindo naturalmente com os colegas e professores, durante as situações de brincar no ambiente aquático; b) o ambiente aquático, por sua vez, mostrou ser um espaço bastante profícuo e facilitador 
da interação da criança autista com os colegas, pela necessidade de contato e colaboração que suscita; c) o repertório de brincar da criança com autismo, apesar de restrito, demonstrou boa evolução na forma de experimentar atividades, explorar o meio líquido, os materiais, os objetos e o seu corpo; d) os jogos apresentados pelo aluno foram em grande parte demonstrações afetivas, aspecto fundamental em qualquer ser humano. As aulas oportunizaram vivências afetivas interessantes ao desenvolvimento do Renato, uma vez que a criança autista costuma apegar-se a algum objeto ou pessoa; e) a ação mediadora do professor de Educação Física foi considerada por nós decisiva para provocar avanços no aprendizado e desenvolvimento das crianças, o que não ocorreria espontaneamente; f) a ação de inclusão desenvolvida se mostrou profícua, facilitando a aproximação e interação dos alunos entre si.

Para além dessas reflexões, destacamos que a participação dos professores/estagiários no processo de intervenção com as crianças foi de suma importância para o desenvolvimento da ação educativa e para a formação inicial desses acadêmicos, como pode ser observado no depoimento de um deles:

Esta experiência me tornou mais ciente da minha responsabilidade na inclusão das crianças com deficiência. Sinto-me muito mais segura para trabalhar com crianças dessa faixa etária e principalmente com crianças com alguma deficiência. Sentir na prática que é possível trabalhar com essas crianças e potencializar o desenvolvimento delas é muito valioso para nós que ainda estamos em formação [...]. Cada vez que lido com as crianças, tenho mais interesse em compreender o universo infantil e suas possibilidades. Meu desejo em atuar na Educação Infantil cresce exponencialmente. $\mathrm{O}$ ambiente alegre, descontraído, criativo e desafiador me instiga a ampliar meus conhecimentos em relação ao papel da Educação Física e do nosso papel enquanto professor de Educação Física na educação dessas crianças e na interação entre as crianças que apresentam deficiência e as que não apresentam deficiência (PROFESSOR/ESTAGIÁRIO 3, diário de campo, em 30 nov. 2010).

Movimento, Porto Alegre, v. 19, n. 02, p. 103-122, abr/jun de 2013. 
Em síntese, podemos considerar que as atividades lúdicas no meio aquático foram benéficas para a criança autista, tanto no sentido da ampliação de seus movimentos e vivências de brincar, como também em suas relações com os professores e as crianças, favorecendo práticas inclusivas.

Como ações futuras, sugerimos a ampliação e criação de novos projetos de atenção às crianças com deficiência em espaços inclusivos, voltados para a oferta de práticas corporais, que tomem em consideração as potencialidades humanas. Como orientações para a prática, o estudo põe em relevo: a atitude acolhedora e mediadora do professor; o trabalho em duplas e em pequenos grupos; a exploração da música (cantigas de roda), que foi uma experiência facilitadora do processo ensino-aprendizagem no trabalho com a criança autista em ambiente inclusivo; a experiência do diálogo e problematização, incentivando a reflexão sobre as diferenças. Cabe ainda destacar a rotina estabelecida com a aula organizada em três momentos - conversa inicial, atividades propriamente ditas e conversa final - como aspectos fundamentais para dar segurança e ordenamento às ações dos estagiários e alunos, possibilitar o diálogo e, principalmente, dar coesão às aulas. 
Ludic activities in aquatic environments: possibilities for inclusion

Abstract: The paper aims at understanding and analyzing the mediator action of the teachers in the development of ludic activities in aquatic environments and the interaction of an autist child with non disabled classmates in the classes. The methodology is based on a qualitative study case. The subjects were 14 children of the Children Education at Universidade Federal do Espírito Santo (UFES) with typical development and an autist one, arising from community da cidade de Vitória no Espírito Santo (ES). Conclude that the ludic activities in the aquatic environment were beneficial for the autist child, in the sense of their movement extension and games experiences, as well as their relation with teachers and classmates.

Keywords: Physical Education. Equity. Swimming. Autistic disorder.

Actividades lúdicas en el medio acuático: posibilidades para la inclusión

Resumen: La investigación tiene como objetivo comprender y analizar la acción mediadora del profesor en el desarrollo de actividades lúdicas en el medio acuático y la interacción de un niño autista con compañeros sin discapacidad en las clases. La metodología se basa en una perspectiva cualitativa con enfoque en un estudio de caso. Los sujetos fueron 14 alumnas y alumnos de la Escuela de Educación Infantil de la Universidade Federal do Espírito Santo (UFES) con desarrollo típico y uno con autismo, todos oriundos de la comunidad da cidade deVitória no Espírito Santo (ES). Concluye que las actividades lúdicas en el medio acuático fueron benéficas para el niño autista, tanto en el sentido de la ampliación de sus movimientos y vivencias de jugar, como también en sus relaciones con los maestros y colegas de clase. Palabras clave: Educación Física. Equidad. Natación. Trastorno autístico. 


\section{REFERÊNCIAS}

BARDIN, Laurence. Análise de conteúdo. Lisboa: Edições 70, 1994.

BROUGÈRE, G. A criança e a cultura lúdica. In: KISHIMOTO, T. M. O brincar e suas teorias. São Paulo: Pioneira, 2002. p. 19-32.

CARMO, Apolônio Abadio do. Inclusão escolar e a educação física: que movimentos são estes? Revista Integração, Brasília, n. 14, p. 6-13, mar. 2002. Ed. especial: Educação Física Adaptada.

UNESCO. CARTA INTERNACIONAL DA EDUCAÇÃO FÍSICA E DO DESPORTO. Disponível em: < http://www.idesporto.pt/DATA/DOCS/LEGISLACAO/doc119.pdf >. Acesso em: 18 maio 2010.

CHICON, José Francisco. Jogo, mediação pedagógica e inclusão: a práxis pedagógica. Vitória, ES: Edufes, 2004.

CRUZ, G. C. Formação continuada de professores de educação física em ambiente escolar inclusivo. Londrina: Eduel, 2008.

DAMASCENO, L. G. Natação, psicomotricidade e desenvolvimento. Brasília: Secretaria dos Desportos da Presidência da República, 1992.

FALKENBACH, A. P. Crianças com crianças na psicomotricidade relacional. Lajeado: Univates, 2005.

FALKENBACH, A. P.; DIESEL, D.; OLIVEIRA, L. C. de. O jogo da criança autista nas sessões de psicomotricidade relacional. Revista Brasileira de Ciências do Esporte, Campinas, v. 31, n. 2, p. 203-214, jan. 2010.

FERNANDES, J. R. P.; LOBO DA COSTA, P. H. Pedagogia da natação: um mergulho para além dos quatro estilos. Revista Brasileira de Educação Física e Esporte, São Paulo, v. 20, n. 1, p. 5-14, jan./mar. 2006.

KISHIMOTO, Tizuko Morchida. Jogos infantis: o jogo, a criança e a educação. 5. ed. Rio de Janeiro: Vozes, 1998.

LEBOYER, Marion. Autismo infantil: fatos e modelos. Campinas, SP: Papirus, 1987.

LEONTIEV, Alex. Os princípios psicológicos da brincadeira pré-escolar. In: VYGOTSKY, Lev Semenovich; LURIA, Alexander Romanovich; LEONTIEV, Alex. Linguagem, desenvolvimento e aprendizagem. 5. ed. São Paulo: Ícone, 1994. p. 119-142 .

MOLINA, R. K. O enfoque teórico metodológico qualitativo e o estudo de caso: uma reflexão introdutória. In: TRIVIÑOS, A. N. S.; MOLINA NETO, V. A pesquisa qualitativa na educação física: alternativas metodológicas. Porto Alegre: UFRGS/ Sulina, 1999. p. 95-105. 


\section{ArtigosOriginais}

NEGRINE, A. S.; MACHADO, M. L. S. Autismo infantil e terapia psicomotriz: estudo de casos. Caxias do Sul: Educs, 2004.

ORRÚ, Sílvia Ester. Autismo, linguagem e educação: interação social no cotidiano escolar. Rio de Janeiro: Wak, 2009.

SÁ, Maria das Graças Carvalho Silva de. Autopercepção de alunos/as com necessidades especiais no cotidiano das aulas de educação física escolar: tecendo redes pelas malhas das experiências instituintes. In: CHICON, José Francisco; RODRIGUES, Graciele Massoli. Educação física e os desafios da inclusão. EDUFES: Vitória, 2010.

SANTOS, Carlos Antônio dos. Natação: ensino e aprendizagem. Rio de Janeiro: Sprint, 1996.

VICTOR, Sonia Lopes. Aspectos presentes na brincadeira de faz-de-conta da criança com Síndrome de Down. 2000. 133 f. Tese (Doutorado em Educação) - Programa de Pós-Graduação da Faculdade de Educação da Universidade de São Paulo (FEUSP), São Paulo, 2000.

VYGOTSKI, L. S. Obras escogidas: fundamentos de defectología. Madrid: Visor, 1997.

VYGOTSKY, Lev Semenovich. A formação social da mente: o desenvolvimento dos processos psicológicos superiores. 4. ed. São Paulo: Martins Fontes, 1991.

Endereço para correspondência:

José Francisco Chicon

Departamento de Ginástica, Centro de Educação Física e Desportos - UFES

Av. Fernando Ferrari, 514

Campus Goiabeiras - Vitória, ES

CEP 29.075-710

Recebido: 8.6.2012

Aprovado: 17.01.2013

Movimento, Porto Alegre, v. 19, n. 02, p. 103-122, abr/jun de 2013. 